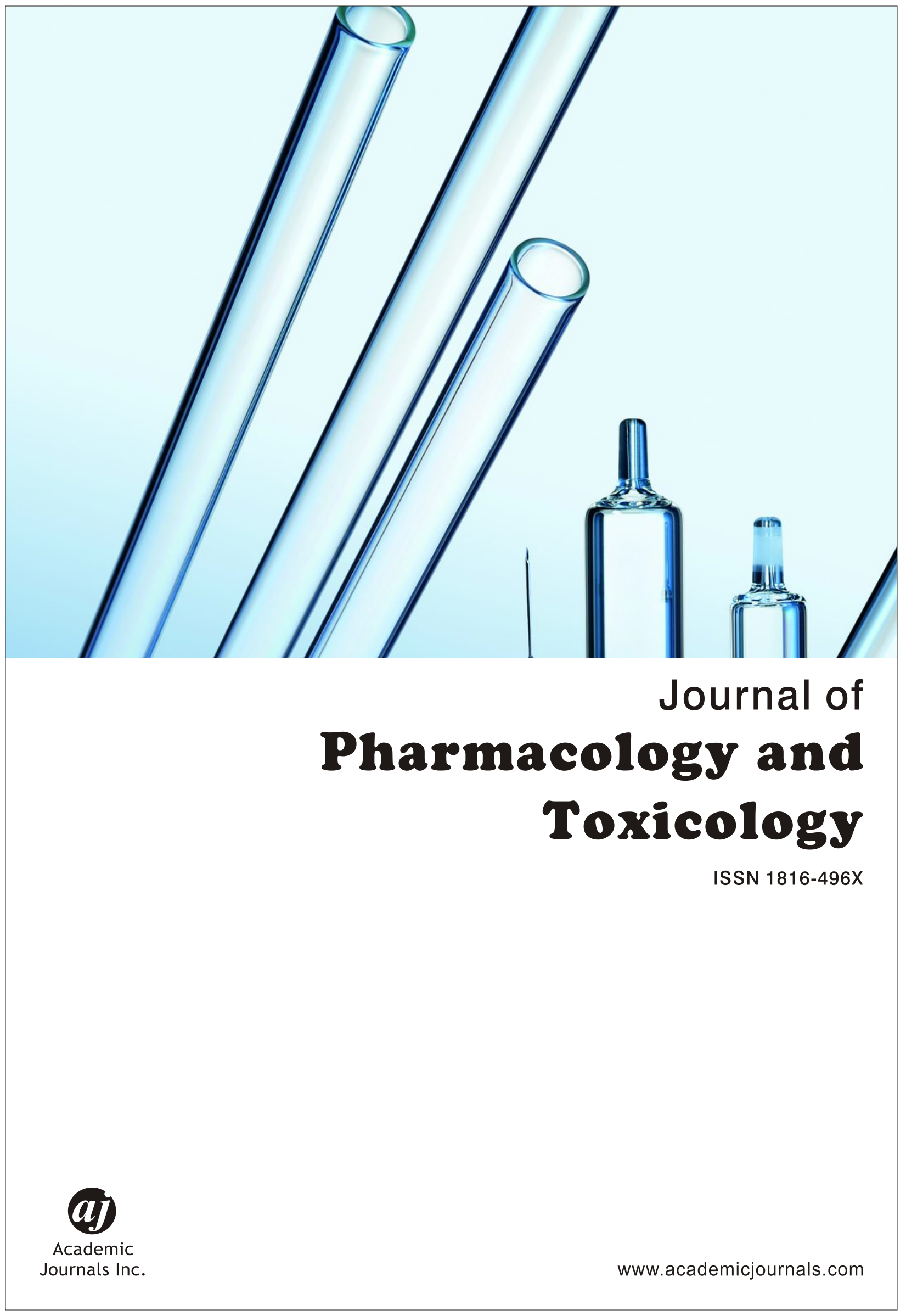




\title{
Pharmacokinetics and Toxicity of Oily Delivery System of Ropivacaine via Subcutaneous Injection in Beagle Dogs
}

\author{
${ }^{1,2}$ Min-Quan Hui, ${ }^{1,2}$ Wu-Dang Lu, ${ }^{1}$ Wei-Ping Yu, ${ }^{2}$ Tao Chen, ${ }^{3}$ Jing-Liang Gu and ${ }^{1}$ Yong-Xiao Cao \\ ${ }^{1}$ Department of Pharmacology, Xi'an Jiaotong University Health Science Center, 76 Yanta West Road, Xi'an, Shaanxi 710061, \\ People Republic of China \\ ${ }^{2}$ Shaanxi Liposome Research Centre, Xi'an, Shaanxi, People Republic of China \\ 3Joinn Laboratories, Inc. Suzhou, Jiangsu, People Republic of China
}

\section{Abstract}

Background and Objective: Ropivacaine, a local anesthetic, can be used for postoperative analgesia but it has certain central and cardiovascular toxicity in high dose. This study investigated the pharmacokinetics and toxicity of oily delivery system ropivacaine in beagle dogs via subcutaneous injection. Materials and Methods: Twelve beagle dogs were randomly divided into ropivacaine oily delivery system and ropivacaine hydrochloride injection group $\left(10 \mathrm{mg} \mathrm{kg}^{-1}\right)$. Liquid chromatography coupled with tandem mass spectrometry method was developed and validated for the determination of plasma ropivacaine. Fifty beagle dogs were divided into five groups, including saline injection group, ropivacaine oily delivery system $\left(15,30\right.$ and $\left.60 \mathrm{mg} \mathrm{kg}^{-1}\right)$ groups and solvent group. The behaviors, pathological changes, electrocardiogram (ECG), blood cell counts, blood biochemistry, urine analysis and histopathological examination were observed. Results: The pharmacokinetic parameters of the oily delivery system of ropivacaine were calculated. The maximum plasma drug concentration $\left(C_{\max }\right)$ was $0.58 \pm 0.25 \mu \mathrm{g} \mathrm{mL}{ }^{-1}$; the time to reach $C_{\max }\left(T_{\text {max }}\right)$ was $11.0 \pm 1.6 \mathrm{~h}$ and the mean residence time $(\mathrm{MRT})$ was $10.62 \pm 1.2 \mathrm{~h}$. Compared with ropivacaine hydrochloride injection, the $C_{\max }$ value was reduced by $80 \%$ and the $T_{\max }$ and $M R T$ values were substantially extended. There was no drug-related changes of toxicology, including behaviors, ECG, blood count, blood clotting, blood biochemistry and urine. Conclusion: Oily delivery system of ropivacaine was retained for longer time than ropivacaine hydrochloride solution in subcutaneous injection in beagle dogs and has no toxicity.

Key words: Ropivacaine, pharmacokinetic, ropivacaine hydrochloride, oily delivery system, drug-related changes, beagle dog

Citation: Min-Quan Hui, Wu-Dang Lu, Wei-Ping Yu, Tao Chen, Jing-Liang Gu and Yong-Xiao Cao, 2018. Pharmacokinetics and toxicity of oily delivery system of ropivacaine via subcutaneous injection in beagle dogs. J. Pharmacol. Toxicol., 13: 37-44.

Corresponding Author: Yong-Xiao Cao, Department of Pharmacology, Xi'an Jiaotong University Health Science Center, 76 Yanta West Road, Xi'an, Shaanxi 710061, People Republic of China Tel: $+86-29-82655140$

Copyright: () 2018 Min-Quan Hui et al. This is an open access article distributed under the terms of the creative commons attribution License, which permits unrestricted use, distribution and reproduction in any medium, provided the original author and source are credited.

Competing Interest: The authors have declared that no competing interest exists. 


\section{INTRODUCTION}

Ropivacaine [(-)-(S)-N-(2,-dimethylphenyl)-1-n-propylpiperidine-2-carboxa-mide] is a classic local anaesthetic, which was developed based on the structures of mepivacaine and bupivacaine ${ }^{1}$. The improved structure of ropivacaine exhibits lower toxicity than mepivacaine and bupivacaine. Ropivacaine inhibits sodium channels located at the drug's site of action on nerve cells to inhibit nerve excitement and conduction. To date, only single ropivacaine $\mathrm{S}$ conformers have been used in clinics. Animal and clinical studies have demonstrated that ropivacaine exerts similar nerve blocking effects to bupivacaine. However, ropivacaine exhibits a stronger effect on sensory nerve block and a weaker effect on the motor nerve block, especially at low concentrations such as $0.5 \%$ or less ${ }^{2,3}$. Therefore, ropivacaine as a postoperative analgesic improves postoperative recovery.

Clinically, ropivacaine mesylate and hydrochloride injections are used for acute postoperative pain control. A single dose of the injection contains up to $300 \mathrm{mg}$, resulting in an analgesic duration of 6-12 h. Such a high dose might lead to a high maximum plasma concentration $\left(C_{\max }\right)$ and induce toxicity. However, for pain management $24-72 \mathrm{~h}$ after an operation and for more intense operative pain, a single injection of either ropivacaine mesylate or hydrochloride injection is insufficient ${ }^{4-6}$.

Patient-controlled regional anaesthesia is a major clinical postoperative analgesia primarily induced by a mixture of local anaesthetic and an opioid administered by epidural injection. The analgesic effect of epidural injection is significant but has many shortcomings, including a high risk of infection at the epidural administration site, the adverse effects of opioids and the need for adequate patient training prior to use. Thus, local anaesthetic nerve block near the wound site gradually becomes the focus of postoperative analgesia. Axelsson et al. studied 40 patients undergoing arthroscopic subacromial decompression in which the surgeon placed a catheter into the subacromial space at the end of the operation. The patients who received a continuous infusion of ropivacaine over a $24 \mathrm{~h}$ period reported a good analgesic effect and exhibited plasma concentrations within the safe range. Kampe et al. ${ }^{8}$ reported two cases of postoperative local tram flap surgery with the continuous infusion of $0.2 \%$ ropivacaine solution through two conduits at a dose of $20 \mathrm{mg} \mathrm{h}^{-1}$ for $48 \mathrm{~h}$, both patients were satisfied with the postoperative analgesia management and exhibited no adverse reactions. Obviously, the continuous infusion of locally administered drug allows for considerable ease of dispensing and can lead to high postoperative management costs.
Some pharmaceutical researchers have noticed this problem. Xu et al. ${ }^{9}$ developed multivesicular liposomes containing ropivacaine hydrochloride that exhibited a high encapsulation efficiency and significant sustained release. $85 \%$ of the particle sizes of the optimized multivesicular liposomes were well distributed in the range of 7-30 $\mu \mathrm{m}$. The encapsulation efficiency was up to $90 \%$ and the in vitro release profile followed first-order kinetics with a release period of up to $48 \mathrm{~h}$ in phosphate-buffered saline ${ }^{9}$ at $37^{\circ} \mathrm{C}$. De Araujo researched ropivacaine in a 2-hydroxypropylcyclodextrin inclusion complex and found that ropivacaine decreased latency without increasing the duration of motor blockade in mice during sciatic nerve blockade studies ${ }^{10}$.

The use of oily delivery system has a long history, including the treatment of women with amenorrhea and dysfunctional uterine bleeding, luteal insufficiency, threatened abortion and habitual abortion. Oily fluorine perphenazine injections have also been implemented clinically for the treatment of schizophrenia. For menopausal women with breast cancer, a palliative injection of testosterone propionate has been used. The safety of lipid-based and oil-based injectables has been recognized by patients. On this basis, a series of ropivacaine formulations reported that were prepared using water-insoluble ropivacaine as the primary drug in conjunction with a non-aqueous drug delivery system. The analgesic effects of local nerve blocks revealed that a 3-4 fold increase of original dose could cause the 7-8 fold increase of analgesic duration compared with the normal formulation ${ }^{11}$. The present study researched the pharmacokinetic and toxicity of oily delivery system of ropivacaine by subcutaneous injection in Beagle dogs for a long duration.

\section{MATERIALS AND METHODS}

\section{Materials}

Reagents and chemicals: Oily delivery system of ropivacaine (30 $\mathrm{mg} \mathrm{mL}^{-1}$ ) was prepared by mixing ropivacaine with benzyl alcohol, benzyl benzoate and soybean oil. Ropivacaine hydrochloride injection (10 mL:100 mg) was purchased from AstraZeneca AB (Sweden). Ropivacaine reference (content: 99.8\%) was obtained from the United States Pharmacopeia Convention, Inc. Bupivacaine (content: 99.6\%) was obtained from the National Institutes for Food and Drug Control (China). Acetonitrile (HPLC grade) was purchased from Fisher Scientific (India) and ammonium acetate (HPLC grade) was purchased from Sigma (Germany).

Animals: The experiments were carried out from JanuarySeptember, 2014 in Joinn Laboratory and Shaanxi Liposome Research Centre. Quarantined beagle dogs (age 7-9 months, 
weight 8-12 kg) were individually housed in cages and was provided food twice daily and hygienic drinking water ad libitum, well-ventilated room that was maintained at a temperature of $16-26^{\circ} \mathrm{C}$ and a relative humidity of $40-70 \%$. Animal care is in compliance with the SOPs of Joinn Laboratories, the Guide for the Care and Use of Laboratory Animals and the US Department of Agriculture through the Animal Welfare Act (Public Law 99-198).

Methods: Liquid chromatography coupled with tandem mass spectrometry (LC-MS/MS) conditions: The detailed method of LC-MS/MS condition was summarized in Table 1 and the product ion spectra was indicated in Fig. 1 and 2.

Method validation: The specificity of the method was conducted by comparing the chromatographs of blank plasma with (1) Blank plasma samples spiked with standard solutions and (2) Plasma samples after subcutaneous injection of drug. Calibration samples (4-2000 $\mathrm{ng} \mathrm{mL}^{-1}$ ) were prepared and the standard calibration curves were obtained by plotting the ratio of peak area of ropivacaine to internal standard against the concentration of ropivacaine. The coefficient of determination $\left(r^{2}\right)$ was calculated, which with a value greater than 0.99 was considered as an indicator of good linearity. The lower limit of quantification (LLOQ) was defined as the lowest concentration of the calibration curve with a signal-to-noise $(\mathrm{S} / \mathrm{N})$ peak ratio greater than 10:1. The intra-day accuracy and precision test were conducted by analyzing samples at nominal concentrations with at least 6 replicates for each concentration within one day. The inter-day accuracy and precision were determined on 3 days separately. Accuracy and precision should be within $\pm 15 \%$ bias and $15 \%$ RSD respectively. The recovery of extraction was determined by the peak area of ropivacaine spiked with the blank plasma followed by extraction against the peak area of ropivacaine spiked to the extracted plasma. The stability of the sample was investigated in different storage conditions, including $25^{\circ} \mathrm{C}$ $(0 \mathrm{~h}, 4 \mathrm{~h}),-15^{\circ} \mathrm{C}$ (7 days and 28 days) and three freeze-thaw cycles.
Pharmacokinetic study: Twelve beagle dogs ( 6 males and 6 females) were divided into two groups: oily ropivacaine delivery system group and ropivacaine hydrochloride injection

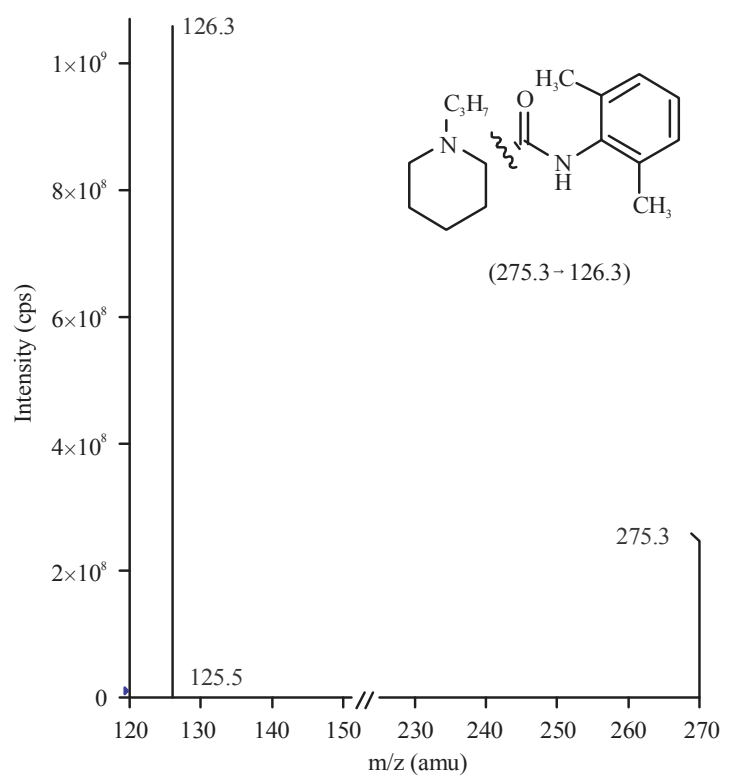

Fig. 1: Product ion spectra of ropivacaine

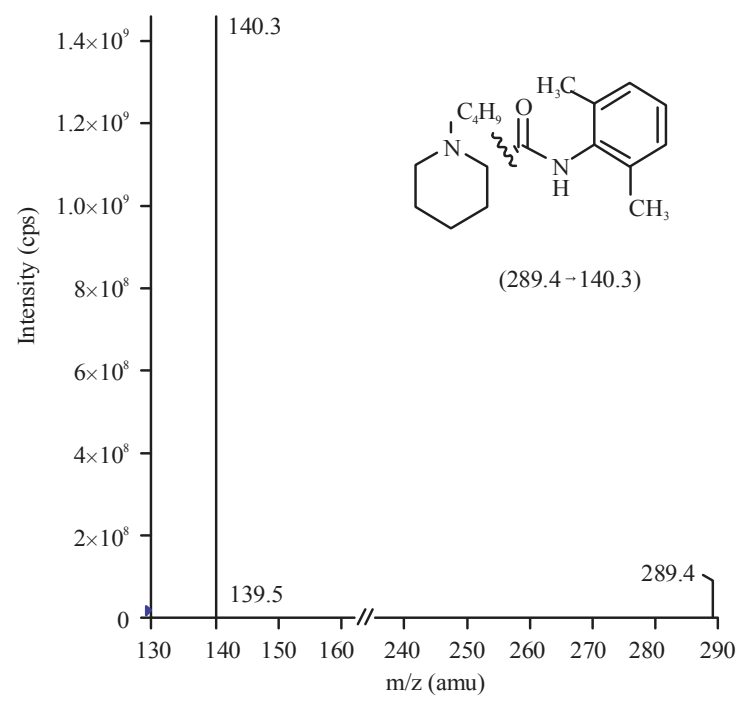

Fig. 2: Product ion spectra of bupivacaine

Table 1: LC-MS/MS condition of pharmacokinetic study

\begin{tabular}{|c|c|c|c|c|c|c|c|}
\hline & \multicolumn{7}{|l|}{ Mobile phase $(\mathrm{v} / \mathrm{v})$} \\
\hline & Injection volume $(\mu \mathrm{L})$ & \multicolumn{2}{|c|}{$5 \mathrm{~mm}$ ammonium acetate } & \multicolumn{2}{|c|}{ Acetonitrile } & \multicolumn{2}{|c|}{ Flow rate $\left(\mathrm{mL} \mathrm{min}^{-1}\right)$} \\
\hline \multirow[t]{2}{*}{ HPLC (LC-30A, SHIMADZU) } & 10 & 5 & & 9 & & 1 & \\
\hline & \multicolumn{7}{|c|}{ Ultimate XB-C18 (4.6×150 mm, $5 \mu \mathrm{m}$, welch materials Inc.) } \\
\hline Column & & Q1 (amu) & Q3 (Amu) & $\mathrm{DP}(\mathrm{V})$ & $E P(V)$ & CE (V) & $\operatorname{CXP}(\mathrm{V})$ \\
\hline \multirow[t]{2}{*}{ MS (4000 QTRAP, Applied Biosystems) } & Ropivacaine & 275.2 & 126.3 & 80 & 10 & 33 & 10 \\
\hline & Internal standard & 289.2 & 140.1 & 90 & 10 & 30 & 20 \\
\hline
\end{tabular}


group. Each group consists of 3 males and 3 female dogs. The animals were subcutaneously injected with respective drugs at a dose of $10 \mathrm{mg} \mathrm{kg}^{-1}$ on their back at multiple locations ( $1 \mathrm{~mL}$ per location). Approximately $1 \mathrm{~mL}$ of blood was collected prior to dosing and at $0.08,0.25,0.5,1,2,4,6,8$, $10,12,24,36,48$ and $72 \mathrm{~h}$ after drug administration. One week after the elution period, two groups of beagle dogs were exchanged and repeated same experiments procedures were repeated.

The blood samples were centrifuged at $8000 \mathrm{rpm}$ for $3.5 \mathrm{~min}$ and the plasma (supernatant) was collected. About $50 \mu \mathrm{L}$ plasma was mixed with $950 \mu \mathrm{L}$ of internal standard (20 $\mathrm{ng} \mathrm{mL}^{-1}$ bupivacaine acetonitrile solution). The mixture was incubated for $1 \mathrm{~min}$ and then was centrifuged at $12000 \mathrm{rpm}$ for $10 \mathrm{~min}$. Next, $20 \mu \mathrm{L}$ of the supernatant was transferred to $380 \mu \mathrm{L}$ sterile water for injection. The solutions were mixed well before analyzed by the LC-MS/MS method summarized in Table 1.

Toxicity study: Fifty beagle dogs ( 25 males and 25 females) were divided into five groups: ropivacaine oily delivery system $15,30,60 \mathrm{mg} \mathrm{kg}^{-1}$, the solvent and saline injection groups. Each group consists of 5 males and 5 female dogs. The drugs were subcutaneously injected at back of the neck for multipoints. The behaviors, respiratory, secretions, vomiting, stool skin, hair, eyes, ears, nose, abdomen, genitalia, anus, legs, feet change of Beagle dogs were observed. Beagle dogs' weight, ECG, body temperature was measured. The beagle dogs were fasted overnight at the 1st day before administration, the 2nd day and the 14th day after administration, respectively, the blood samples were collected from forelimb vein for analysis of blood cells and biochemistry. Urine of beagle dogs was collected and tested on the 1st day before administration and the 13th day after administration for general inspection. Beagle dogs ( 2 males and 2 females) of each group on the 3rd day and other dogs on the 15th day after the administration were euthanized, dissected for histopathological inspection.

Data analysis: Analyst 1.6 software (AB SCIEX, USA) was used to prepare the raw chromatograms. Statistical analyses were conducted using GRAPH-PAD PRISM 5.0 (GraphPad Software, La Jolla, CA, USA). The pharmacokinetic parameters were calculated by a non-compartmental model approach (NCA) implemented in WinNonlin (V6.2) software. The data were expressed as the Means $\pm S D$. $p<0.05$ was considered to be statistically significant.

\section{RESULTS}

Specificity: In Fig. 3, the peak intensity of blank plasma was very low (Fig. 3a). The retention time of ropivacaine and bupivacaine were 2.83 and $3.11 \mathrm{~min}$, respectively. The intensity of the ropivacaine peak (Fig. 3b) in its LLOQ was about 10 times higher than that in the blank plasma and the intensity of the internal standard-bupivacaine peak (Fig. 3c) was about 2400 times higher than that in blank plasma. The influence of the blank plasma on the quantification of ropivacaine and bupivacaine could be neglected. Therefore, there was no interfering peak near the retention times of ropivacaine and the internal standard, suggesting that a good specificity was achieved.

Standard curve, precision and accuracy: Within the range of the standard curve (4-2000 $\left.\mathrm{ng} \mathrm{mL}^{-1}\right)$, the LLOQ of ropivacaine

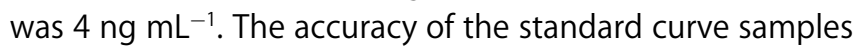
ranged from $92.06 \%$ to $111.61 \%$, and the correlation coefficient was 0.9981 (Data not shown), meeting requirements. As indicated in Table 2, the average accuracy of the quality control samples ranged from $102.18-111.58 \%$. The average precision ranged from $3.05-6.81 \%$.

Stability: As indicated in Table 3, the recovery rate of ropivacaine plasma sample is ranged from $95.84-109.64 \%$ when the samples were placed at less than $-15^{\circ} \mathrm{C}$ for different times or were subjected to three rounds of freeze-thaw (at least $12 \mathrm{~h}$ per round) or stored at room temperature for different times.

\section{Pharmacokinetics of ropivacaine in ropivacaine oily injection or ropivacaine hydrochloride after subcutaneous injection: The plasma concentrations of ropivacaine in} each group were presented in Table 4, respectively. About $0.083 \mathrm{~h}$ after the subcutaneous injection, the drug concentrations in both groups could be detected and the concentration in ropivacaine hydrochloride group was $1768.61 \pm 859.86 \mathrm{ng} \mathrm{mL}^{-1}$, which was more than 30 folds higher than that in ropivacaine oily delivery system group $\left(57.25 \pm 28.80 \mathrm{ng} \mathrm{mL}^{-1}\right)$. However, the drug concentration in the ropivacation hydrochloride group decreased rapidly, whereas, the drug concentration in ropivacaine oily delivery system group was kept increasing in the first $12 \mathrm{~h}$. At $6 \mathrm{~h}$ after the injection, the drug concentration in two groups was comparable and for the time points of 6-12 $h$, the drug concentration in the ropivacaine oily delivery system group was larger than that in ropivacaine hydrochloride group. At $12 \mathrm{~h}$ after the injections of ropivacaine oily delivery system, the drug concentration was the highest $\left(400.67 \pm 199.35 \mathrm{ng} \mathrm{mL}^{-1}\right)$, 

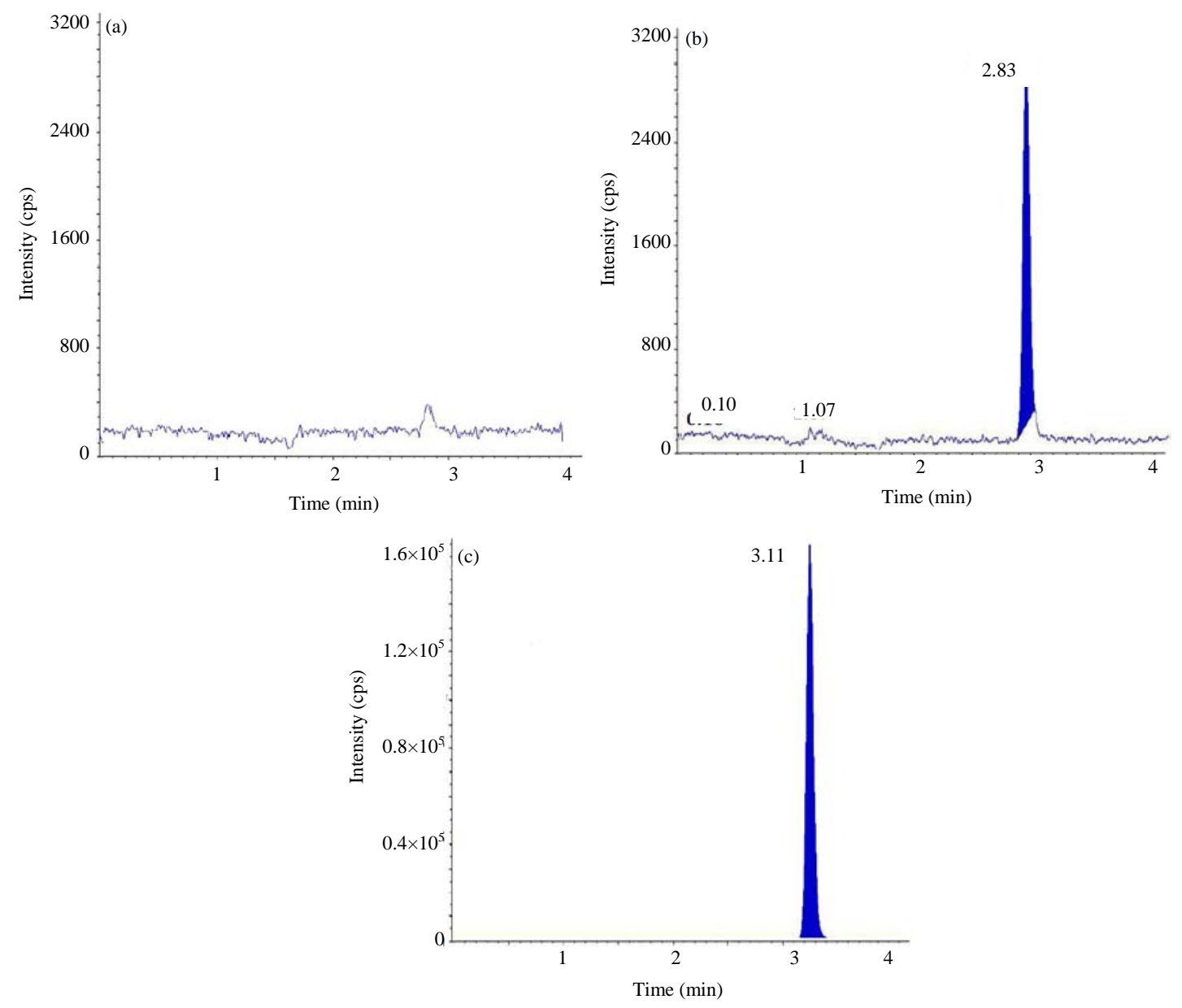

Fig. 3(a-c): Typical specificity graph for the validation of ropivacaine determination in beagle dogs. Plasma drug concentrations were determined quantitatively by LC-MS/MS, (a) Blank plasma, (b) Ropivacaine (LLOQ, $4 \mathrm{ng} \mathrm{mL}^{-1}$ ) and (c) Bupivacaine (internal standard)

Table 2: Extraction recoveries of ropivacaine in plasma and intra-day, inter-day accuracy and precision of the method $(n=6)$

\begin{tabular}{|c|c|c|c|c|c|c|c|c|c|}
\hline \multirow[b]{2}{*}{ Matrix } & \multirow[b]{2}{*}{$\begin{array}{l}\text { Spiked } \\
\text { conc. }\left(\mathrm{ng} \mathrm{mL}^{-1}\right)\end{array}$} & \multirow[b]{2}{*}{ Linearity } & \multirow[b]{2}{*}{$\begin{array}{l}\text { Extraction } \\
\text { recovery (\%) }\end{array}$} & \multicolumn{3}{|l|}{ Intra day $(n=6)$} & \multicolumn{3}{|l|}{ Inter day $(n=6)$} \\
\hline & & & & $\begin{array}{l}\text { Determined } \\
\text { conc. }\left(\mathrm{ng} \mathrm{mL}^{-1}\right)\end{array}$ & $\begin{array}{l}\text { Precision } \\
\text { (RSD\%) }\end{array}$ & Accuracy (\%) & $\begin{array}{l}\text { Determined } \\
\text { conc. }\left(\mathrm{ng} \mathrm{mL}^{-1}\right)\end{array}$ & $\begin{array}{l}\text { Precision } \\
\text { (RSD\%) }\end{array}$ & Accuracy (\%) \\
\hline \multirow[t]{3}{*}{ Plasma } & 12 & 0.9999 & $116.25 \pm 3.46$ & $13.39 \pm 0.91$ & 6.81 & 111.58 & $12.29 \pm 0.68$ & 5.24 & 102.42 \\
\hline & 80 & 1.0000 & $116.24 \pm 4.33$ & $87.51 \pm 4.06$ & 4.64 & 109.39 & $84.78 \pm 4.08$ & 4.82 & 105.98 \\
\hline & 800 & 0.9998 & $104.40 \pm 3.34$ & $833.71 \pm 34.05$ & 4.08 & 104.21 & $817.43 \pm 24.93$ & 3.05 & 102.18 \\
\hline
\end{tabular}

Table 3: Stability of ropivacaine under different conditions in beagle dog plasma by LC-MS/MS $(n=3)$

\begin{tabular}{|c|c|c|c|c|c|c|c|}
\hline Matrix & $\begin{array}{l}\text { Spiked } \\
\text { conc. }\left(\mathrm{ng} \mathrm{mL}^{-1}\right)\end{array}$ & 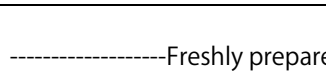 & 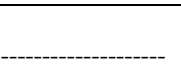 & $25^{\circ} \mathrm{C}$ for $4 \mathrm{~h}$ & 3 freeze-thaw cycles & $\begin{array}{l}\text { Below- } 15^{\circ} \mathrm{C} \\
\text { for } 7 \text { days }\end{array}$ & $\begin{array}{l}\text { Below- } 15^{\circ} \mathrm{C} \\
\text { for } 28 \text { days }\end{array}$ \\
\hline \multirow[t]{4}{*}{ Plasma } & 12 & Determined conc. $\left(\mathrm{ng} \mathrm{mL}^{-1}\right)$ & $12.71 \pm 0.10$ & $12.68 \pm 0.40$ & $12.41 \pm 0.57$ & $13.16 \pm 0.47$ & $12.15 \pm 0.40$ \\
\hline & & Recovery (\%) & $105.92 \pm 0.82$ & $105.64 \pm 3.19$ & $103.42 \pm 4.55$ & $109.64 \pm 3.59$ & $101.28 \pm 3.25$ \\
\hline & 800 & Determined conc. $\left(\mathrm{ng} \mathrm{mL}^{-1}\right)$ & $817.29 \pm 31.89$ & $808.77 \pm 30.27$ & $799.60 \pm 6.06$ & $795.34 \pm 5.76$ & $766.73 \pm 8.94$ \\
\hline & & Recovery (\%) & $102.16 \pm 3.90$ & $101.10 \pm 3.74$ & $99.95 \pm 0.76$ & $99.42 \pm 0.72$ & $95.84 \pm 1.17$ \\
\hline
\end{tabular}

which is more than 2.5 folds higher than that in the ropivacaine hydrochloride group $\left(156.14 \pm 56.08 \mathrm{ng} \mathrm{mL}^{-1}\right)$. $12 \mathrm{~h}$ later, the drug concentration in ropivacaine oily delivery system group decreased quickly and only $4.41 \pm 6.24 \mathrm{ng} \mathrm{mL}^{-1}$ could be detected $48 \mathrm{~h}$ after the injection. No ropivacaine could be detected in the plasma for either group $72 \mathrm{~h}$ after the injection.

The pharmacokinetic data was also analyzed non-compartmentally by WinNonlin (Certara USA, Inc., Princeton, NJ, USA) and the resulted pharmacokinetic 


\begin{tabular}{|c|c|c|}
\hline \multirow[b]{2}{*}{ Time (h) } & \multicolumn{2}{|c|}{ Ropivacaine concentration in plasma $\left(\mathrm{ng} \mathrm{mL}^{-1}\right)$} \\
\hline & Ropivacaine oily delivery system & Ropivacaine hydrochloride \\
\hline 0.083 & $57.25 \pm 28.80$ & $1768.61 \pm 859.86$ \\
\hline 0.25 & $157.42 \pm 94.06$ & $1892.67 \pm 1186.12$ \\
\hline 0.5 & $235.32 \pm 145.11$ & $1635.97 \pm 1091.40$ \\
\hline 1 & $230.20 \pm 154.34$ & $1091.56 \pm 778.08$ \\
\hline 2 & $180.85 \pm 117.53$ & $554.57 \pm 412.85$ \\
\hline 4 & $228.20 \pm 109.98$ & $432.44 \pm 308.13$ \\
\hline 6 & $277.71 \pm 157.55$ & $416.74 \pm 314.02$ \\
\hline 8 & $319.52 \pm 200.25$ & $304.20 \pm 197.76$ \\
\hline 10 & $383.62 \pm 221.51$ & $220.66 \pm 106.81$ \\
\hline 12 & $400.67 \pm 199.35$ & $156.14 \pm 56.08$ \\
\hline 24 & $68.64 \pm 26.33$ & $118.45 \pm 22.10$ \\
\hline 36 & $12.01 \pm 2.60$ & $12.80 \pm 4.45$ \\
\hline 48 & $4.41 \pm 6.24$ & 0.00 \\
\hline 72 & 0.00 & 0.00 \\
\hline
\end{tabular}

Table 5: A comparison of pharmacokinetic parameters of oily delivery system of ropivacaine and ropivacaine hydrochloride injection $($ Mean $\pm S D, n=12)$

\begin{tabular}{lcc}
\hline Parameters & Ropivacaine oily delivery System & Ropivacaine hydrochloride injection \\
\hline $\mathrm{t}_{1 / 2}(\mathrm{~h})$ & $4.54 \pm 0.85^{* *}$ & $3.06 \pm 0.96$ \\
$\mathrm{~T}_{\max }(\mathrm{h})$ & $11.00 \pm 1.60^{* *}$ & $0.22 \pm 0.07$ \\
$\mathrm{C}_{\max }\left(\mathrm{g} \mathrm{mL}^{-1}\right)$ & $0.58 \pm 0.25^{* *}$ & $2.76 \pm 1.09$ \\
$\mathrm{AUC} C_{\text {last }}\left(\mu \mathrm{g} \mathrm{h} \mathrm{mL}^{-1}\right)$ & $9.02 \pm 3.64$ & $7.93 \pm 2.09$ \\
$\mathrm{AUC} \mathrm{C}_{\infty}\left(\mathrm{g} \mathrm{h} \mathrm{mL}^{-1}\right)$ & $9.21 \pm 3.60$ & $8.26 \pm 2.15$ \\
$\mathrm{Vd}\left(\mathrm{L} \mathrm{kg}^{-1}\right)$ & $7.98 \pm 3.07$ & $5.69 \pm 2.39$ \\
$\mathrm{Cl}\left(\mathrm{L} \mathrm{h} \mathrm{kg}^{-1}\right)$ & $1.22 \pm 0.40$ & $1.29 \pm 0.34$ \\
$\mathrm{MRT}_{\text {last }}(\mathrm{h})$ & $10.62 \pm 1.20^{* *}$ & $3.87 \pm 1.17$ \\
\hline
\end{tabular}

${ }^{* *} p<0.01$ vs. ropivacaine hydrochloride injection

parameters were summarized in Table 5 . The $T_{\max }$ in ropivacaine oily delivery system was $11.00 \pm 1.60 \mathrm{~h}$, which was 50 times of that of ropivacaine hydrochloride group $(0.22 \pm 0.07 \mathrm{~h}, \mathrm{p}<0.01)$. The $\mathrm{C}_{\max }$ of oily delivery system of ropivacaine group $\left(0.58 \pm 0.25 \mu \mathrm{g} \mathrm{mL} \mathrm{L}^{-1}\right)$ was significantly less than that of ropivacaine hydrochloride group $\left(2.76 \pm 1.09 \mu \mathrm{g} \mathrm{mL}^{-1}\right)$. The $A \cup C_{\infty}$ and $A \cup C_{\text {last }}$ were comparable between two groups (for ropivacaine hydrochloride group the $A \cup C_{\infty}$ is $8.26 \pm 2.15 \mu \mathrm{g} \mathrm{h} \mathrm{mL}^{-1}$ and for ropivacaine oily delivery system group the $A \cup C_{\infty}$ is $9.21 \pm 3.60 \mu \mathrm{g} \mathrm{mL}^{-1}$ ). The MRT of oily delivery system of ropivacaine group was $10.62 \pm 1.20 \mathrm{~h}$, which was 2.7 times of that of ropivacaine hydrochloride group $(3.87 \pm 1.17 \mathrm{~h})(\mathrm{p}<0.01)$. This results suggested that the duration of ropivacaine oily delivery system in the plasma is longer than that of the control.

Toxicity: There was no significant difference of the body temperature, weight and electrocardiogram and other physical properties before and after the administration of ropivacaine oily delivery system. Also, there was no significant difference in hematology indicators, blood biochemical indicators and histopathology between ropivacaine oily delivery system and saline solution group. To sum up, no toxicity effect was observed after the administration of ropivacaine oily delivery system.

\section{DISCUSSION}

A LC-MS/MS method was developed and validated to study the pharmacokinetic of ropivacaine in beagle dogs. The method is good in specificity, linearity, accuracy, precision, recovery and stability.

As indicated in Table 5, there was no significant different of the AUC $\infty$ between two groups, suggesting that absorption of ropivacaine in two groups is at the same level. The MRT of the ropivacaine oily delivery system is 2.7 times of that of the ropivacaine hydrochloride. $T_{\max }$ of the ropivacaine oily delivery system is much larger than that of ropivacaine hydrochloride injection. Furthermore, compared with the $t_{1 / 2}$ of ropivacaine hydrochloride group, the $t_{1 / 2}$ of ropivacaine oily delivery system was delayed by about $1.5 \mathrm{~h}$. These results indicate that when formulated into the oily delivery system, ropivacaine was slowly released from the site of injection, and ropivacaine oily delivery system can maintain much longer duration and more powerful analgesia effect than ropivacaine hydrochloride. 
It is reported that overdosage ropivacaine showed obvious toxic effects both in animals and human. When sheep were intravenously injected with ropivacaine hydrochloride solution of $90-120 \mathrm{mg}$, they showed startle reactions and cardiovascular problems such as changes in heart rate, mean arterial pressure, cardiac output, systemic vascular resistance, left ventricular end diastolic pressure and myocardial contractility ${ }^{12}$; intravenously injection of ropivacaine hydrochloride at $7 \mathrm{mg} \mathrm{kg}^{-1}$ decreased blood pressure and cardiac index in pigs ${ }^{13}$; intravenous injection of $2.6 \mathrm{mg} \mathrm{kg}^{-1}$ ropivacaine could lead to symptoms of convulsive induced contraction, a loss of righting reflex, weakness of autonomic activities and respiratory depression in rats and intravenous injection of $0.5 \%$ ropivacaine at a rate of $2 \mathrm{mg} \mathrm{kg}$ $\mathrm{min}^{-1}$ in rats could cause arrhythmia and arrhythmia $30 \mathrm{~min}$ after the administration ${ }^{14,15}$.

In a clinical study, three volunteers who were injected ropivacaine hydrochloride injection, resulted in dysphoria, anxiety and screaming ${ }^{16}$. It was reported that when dosing with dosage ${ }^{17}$ of $300 \mathrm{mg}$, ropivacaine showed central nervous system toxicity in two patients for infraclavicular block; 30 adult female patients who received gynaecological laparotomy had a potentially high enough ropivacaine plasma concentration to cause systemic toxicity and three of them reported symptoms of mild neurotoxicity and elevated mean peak levels $\left(2.70 \mu \mathrm{g} \mathrm{mL}^{-1}\right)^{18}$. In a study of the effects of bilateral thoracic paravertebral block, one patient developed local anaesthetic toxicity after receiving infusion of $0.25 \%$ ropivacaine $0.1 \mathrm{~mL} \mathrm{~kg} \mathrm{~h}^{-1}$ at the end of the surgery ${ }^{19}$.

When the ropivacaine was formulated into an oily delivery system, the plasma $C_{\max }$ was significantly decreased. The $C_{\max }$ of ropivacaine oily delivery system is about one fifth of ropivacaine hydrochloride injection. It was observed that when ropivacaine was formulated into the oily delivery system, the $C_{\max }$ was significantly lower which may decrease the possibility of systemic adverse reactions. This was proved by the acute toxicity study, in which, no behavioral abnormal, nerve or cardiovascular toxicity were observed in beagle dogs when ropivacaine $60 \mathrm{mg} \mathrm{kg}^{-1}$ was subcutaneous injected. The dose was about 20 fold of the clinical dosage of hydrochloric ropivacaine injection. The results indicated that ropivacaine oily delivery system is safe.

\section{CONCLUSION}

Oily delivery system of ropivacaine can slowly and continuously release ropivacaine, which benefits sustained analgesics. No any toxicity was observed in dogs. Therefore, oily delivery system of ropivacaine might provide strong support for follow-up clinical studies.

\section{SIGNIFICANCE STATEMENT}

This study found that the ropivacaine oily delivery system has a long-lasting nerve block and is highly safe. The study helped researchers unravel the In vivo release characteristics of ropivacaine oil solution after subcutaneous administration. It provided theoretical support for the application of oily agents in the field of analgesics.

\section{ACKNOWLEDGMENTS}

This study was supported by Chinese Ministry of Science and Technology Innovation Fund for small and medium enterprises (Project code: 13CR6R16105758).

\section{REFERENCES}

1. Akerman, B., I.B. Hellberg and C. Trossvik, 1988. Primary evaluation of the local anaesthetic properties of the amino amide agent ropivacaine (LEA 103). Acta Anaesthesiol. Scand., 32: 571-578.

2. McClure, J.H., 1996. Ropivacaine. Br. J. Anaesth., 76: 300-307.

3. Zink, W. and B.M. Graf, 2008. The toxicity of local anesthetics: The place of ropivacaine and levobupivacaine. Curr. Opin. Anesthesiol., 21: 645-650.

4. Vinson-Bonnet, B., J.C. Coltat, A. Fingerhut and F. Bonnet, 2002. Local infiltration with ropivacaine improves immediate postoperative pain control after hemorrhoidal surgery. Dis. Colon Rectum, 45: 104-108.

5. Sommer, M., J.M. de Rijke, M. van Kleef, A.G. Kessels and M.L. Peters et al., 2008. The prevalence of postoperative pain in a sample of 1490 surgical inpatients. Eur. J. Anaesthesiol., 25: 267-274.

6. Kanata, K., S. Sakura, H. Kushizaki, T. Nakatani and Y. Saito, 2006. Effects of epidural anesthesia with 0.2 and $1 \%$ ropivacaine on predicted propofol concentrations and bispectral index values at three clinical end points. J. Clin. Anesth., 18: 409-414.

7. Axelsson, K., U. Nordenson, E. Johanzon, N. Rawal, G. Ekback, G. Lidegran and A. Gupta, 2003. Patient Controlled Regional Analgesia (PCRA) with ropivacaine after arthroscopic subacromial decompression. Acta Anaesthesiol. Scand., 47: 993-1000.

8. Kampe, S., M. Warm, S.M. Kasper and C. Diefenbach, 2003. Concept for postoperative analgesia after pedicled TRAM flaps: Continuous wound instillation with $0.2 \%$ ropivacaine via multilumen catheters. A report of two cases. Br. J. Plastic Surg., 56: 478-483. 
9. Xu, S.J., J.S. Tu and H. Pang, 2009. Preparation of ropivacaine hydrochloride multivesicular liposomes and release in vitro. J. China Pharm. Univ., 40: 213-217.

10. De Araujo, D.R., S.S. Tsuneda, C.M.S. Cereda, F.D.G.F. Carvalho and P.S.C. Prete et al., 2008. Development and pharmacological evaluation of ropivacaine-2-hydroxypropyl$\beta$-cyclodextrin inclusion complex. Eur. J. Pharm. Sci., 33:60-71.

11. Lu, W.D., W.P. Yu, T. Chen, J.L. Gao and D.F. Kong et al., 2013. The composition and preparation of non-addictive sustained release drug delivery for local anesthetic. China Patent No. 103142458A.

12. Rutten, A.J., C. Nancarrow, L.E. Mather, A.H. Ilsley, W.B. Runciman and R.N. Upton, 1989. Hemodynamic and central nervous system effects of intravenous bolus doses of lidocaine, bupivacaine and ropivacaine in sheep. Anesth. Analg., 69: 291-299.

13. Bonfim, M.R., M.D.S. Melo, E. Dreyer, L.F.A. Borsoi, T.G. de Oliveira and T.S.A.A. Udelsmann, 2012. Lipid therapy with two agents in ropivacaine-induced toxicity: Experimental study in swine. Rev. Bras. Anestesiol., 62: 690-695.

14. Yang, J.L., X.Z. Yang and H.C. Guo, 2016. Study on rat's systematic acute toxicity of ropivacaine. Med. Innov. China, 27: 17-19.
15. Wang, C.A., X. Xu, W. Jin, S.T. Wang and X.F. Liu, 2016. The effect of acupoint injection Puerarin on ropivacaine infusion induced cardiac toxicity in rats. Internal Med. China, 2: 179-181.

16. Klein, S.M. and H. Benveniste, 1999. Anxiety, vocalization and agitation following peripheral nerve block with ropivacaine. Reg. Anesth. Pain Med., 24: 175-178.

17. Yang, C.W., P.S. Kang, H.U. Kwon and D.J. Lim, 2012. High dose ropivacaine-induced toxicity after infraclavicular block. Korean J. Anesthesiol., 62: 96-97.

18. Griffiths, J.D., N.V. Le, S. Grant, A. Bjorksten, P. Hebbard and C. Royse, 2013. Symptomatic local anaesthetic toxicity and plasma ropivacaine concentrations after transversus abdominis plane block for Caesarean section. Br. J. Anaesth., 110: 996-1000.

19. Ho, A.M., M.K. Karmakar, S.K. Ng, S. Wan and C.S.H. Ng et al., 2016. Local anaesthetic toxicity after bilateral thoracic paravertebral block in patients undergoing coronary artery bypass surgery. Anaesth. Intensive Care, 44: 615-619. 